available at www.sciencedirect.com

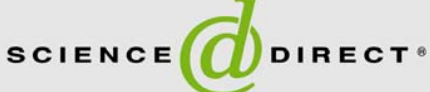

journal homepage: www.ejconline.com

\title{
Review
}

\section{Recent developments in the use of chemotherapy in brain tumours}

\author{
Martin J. van den Bent ${ }^{a, *}$, Monika E. Hegi ${ }^{b}$, Roger Stupp ${ }^{c}$ \\ ${ }^{a}$ Department of Neuro-Oncology, Daniel den Hoed Cancer Center/Erasmus University Hospital Rotterdam, P.O. Box 5201, \\ 3008AE Rotterdam, The Netherlands \\ ${ }^{\mathrm{b}}$ Laboratory of Tumour Biology and Genetics, Department of Neurosurgery, University of Lausanne Hospitals, Lausanne, Switzerland \\ ${ }^{\mathrm{c}}$ Multidisciplinary Oncology Center, University of Lausanne Hospitals, Lausanne, Switzerland
}

\section{A R T I C L E I N F O}

Article history:

Received 27 June 2005

Accepted 29 June 2005

Available online 20 January 2006

Keywords:

Glioblastoma

Oligodendroglioma

Anaplastic glioma

Temozolomide

Radiotherapy

PCV

MGMT

\begin{abstract}
A B S T R A C T
Several recent studies have further clarified the role of chemotherapy in newly diagnosed anaplastic glioma. For newly diagnosed glioblastoma, combined daily radiotherapy with daily temozolomide followed by six cycles of adjuvant temozolomide improves overall survival. This benefit is especially observed in patients with a methylated promotor of the MGMT gene which encodes an alkyltransferase; this observation however, needs confirmation. Although oligodendroglial tumours are sensitive to chemotherapy, classical adjuvant nitrosourea-based chemotherapy does not improve overall survival in newly diagnosed anaplastic oligodendroglioma, even in the subset of $1 \mathrm{p} / 19 \mathrm{q}$ loss tumours. It may increase progression-free survival however, and further studies must show if combined modality treatment with daily chemotherapy during radiotherapy increases survival. Trials exploring the role of chemotherapy in low-grade glioma are ongoing. No standard chemotherapy is currently available for highly anaplastic glioma failing first-line temozolomide-based therapy.
\end{abstract}

(c) 2005 Elsevier Ltd. All rights reserved.

\section{Introduction}

Randomized trials on malignant glioma conducted from 1970 to the 1990s clearly established the role of radiotherapy in the treatment of anaplastic glioma, but all failed to demonstrate a significant increase in survival by the addition of chemotherapy (Table 1). ${ }^{1,2}$ It took a large individual patient data based meta-analysis comprising over 3000 patients to show that adjuvant chemotherapy may improve the 2-year survival by only $5 \%$, from $15 \%$ to $20 \%{ }^{3}$ In recent years, the role of chemotherapy in glioma has been met with renewed interest mainly due to two developments: the recognition of the sensitivity to chemotherapy of $1 \mathrm{p} / 19 \mathrm{q}$ loss oligodendrogliomas; and the availability of temozolomide, a novel alkylating agent with good penetration in the central nervous system. In the 1990s a series of phase II trials have shown activity of temozolomide (TMZ) against recurrent glioblastoma and anaplastic astrocytoma. After approval in 1999, TMZ has largely replaced nitrosoureas in the treatment of glioma, although a formal comparative trial was never conducted. Recently, a randomized trial has demonstrated a superior survival in newly diagnosed glioblastoma multiforme (GBM) patients, treated with TMZ and radiation. ${ }^{4}$ Both PCV combination chemotherapy (procarbazine, CCNU and vincristine) and temozolomide were investigated as treatment for recurrent and newly diagnosed anaplastic oligodendrogliomas. This review

\footnotetext{
* Corresponding author: Tel.: +31 10 4391415; fax: +31 104391031.

E-mail address: m.vandenbent@erasmusmc.nl (M.J. van den Bent). 0959-8049/\$ - see front matter (c) 2005 Elsevier Ltd. All rights reserved. doi:10.1016/j.ejca.2005.06.031
} 
Table 1 - Median, 1- and 2-year survival after various postoperative adjuvant treatment in high-grade glioma, in bold the outcome of EORTC study 26981

\begin{tabular}{|c|c|c|c|c|}
\hline Reference & Treatment & Median survival & 1-year survival (\%) & 2-year survival (\%) \\
\hline \multirow[t]{4}{*}{ Walker $1978^{1}$} & Supportive care & $3 \mathrm{mo}$ & 3 & 0 \\
\hline & BCNU & $4 \mathrm{mo}$ & 12 & 0 \\
\hline & $\mathrm{RT}$ & $8 \mathrm{mo}$ & 24 & 1 \\
\hline & $\mathrm{RT}+\mathrm{BCNU}$ & $8 \mathrm{mo}$ & 32 & 5 \\
\hline \multirow[t]{2}{*}{ Glioma Meta-analysis Trialists Group ${ }^{3}$} & RT & & 40 & 15 \\
\hline & $\mathrm{RT}+\mathrm{CTX}$ & & 46 & 20 \\
\hline \multirow[t]{2}{*}{ EORTC $26981^{4}$} & $\mathrm{RT}$ & 12 & 51 & 10 \\
\hline & $\mathrm{RT}+$ temozolomide & 15 & 61 & 27 \\
\hline
\end{tabular}

RT, radiotherapy; CTX, chemotherapy; SRS, stereotactic radiosurgery; BCNU, carmustine; mo, months.

will summarize the current knowledge in the field, and aims to highlight some novel developments and directions for future research.

\section{Temozolomide: pharmacology and mechanisms of action}

TMZ is an oral alkylating agent, which is rapidly (peak concentrations after 30-90 min) absorbed, penetrates into all body tissues including the central-nervous system and spontaneously converts into the active metabolite MTIC. ${ }^{5}$ Although recommended to be taken in fasting state, food will have little influence with a $10 \%$ reduced AUC and a delayed peak concentration. ${ }^{6}$ Similar to nitrosoureas, TMZ acts as a DNA alkylating agent. Alkylation of the 06-position of guanine is one among many DNA adducts formed, but it is of major importance for the induction of mutations and the cytotoxic action of these drugs. During subsequent DNA replication, the methylated guanine could be shown to be paired with thymidine instead of cytidine, which initiates futile mismatch repair and eventually may induce apoptosis. Cells have the capacity of restoring guanine through the DNA excision repair enzyme $\mathrm{O}^{6}$-methylguanine-DNA methyltransferase (MGMT), also known as $\mathrm{O}^{6}$-alkyl-guanine-alkyltransferase (AGAT) (reviewed by Gerson ${ }^{7}$ ). During this saturable process the enzyme is consumed. High endogenous MGMT activity in cancer cells blunts the treatment-effect of alkylating agent chemotherapies creating a resistant phenotype and may be an important determinant of treatment failure. ${ }^{8-12}$ Silencing the MGMT gene by promoter methylation that impairs expression of the DNA repair enzyme has been associated with prolonged survival in glioma patients treated with nitrosoureas or with TMZ. ${ }^{13,14}$

\section{Temozolomide in recurrent glioma}

TMZ has demonstrated its activity initially in patients with recurrent high-grade glioma. Three pivotal phase II studies with identical entry criteria were conducted for patients with GBM and with anaplastic astrocytoma (AA). Despite disappointingly low objective response rates in GBM of $5 \%$ and $7 \%$, respectively, but with an interesting response rate of $35 \%$ in the AA trial, these studies suggested an increase in the fraction of patients being progression-free at 6 months compared to a historical database. ${ }^{15-17}$ Subgroup analysis suggested that mainly patients who had not received prior adjuvant chemotherapy benefited from this treatment.

\section{Temozolomide schedules}

In vitro and phase I studies have established the initial standard dosing of TMZ (150-200 mg/m²/day) for 5 days every 4 weeks. Novel continuous administration schedules have since been developed, allowing for more intensive and dosedense regimens. Using these low-dose but daily schedules, the actual dose-intensities could be increased up to over 2fold (e.g., one week on/one week off, three weeks on/one week off, 42 days every 60 days). ${ }^{18-20}$ The protracted administration of temozolomide, even at relatively low daily doses, was shown to lead to significant and prolonged depletion of MGMT activity. ${ }^{21}$ Although this may potentially enhance the antitumour activity of the agent, to date there are no conclusive data available demonstrating that these more dose-dense regimens offer clinically relevant increased anti tumour activity. ${ }^{22,23}$ No randomized studies exist, and the reported improved outcome in terms of 6 months progression-free survival may be a matter of patient selection. One novel adverse effect of the continuous temozolomide administration schedules is induction of profound lymphocytopenia with low CD4 counts. ${ }^{24}$ The common use of corticosteroids in brain tumour patients adds further to an immunodeficient state, predisposing patients to opportunistic infections. Increased incidence of opportunistic infections, in particular pneumocystis carinii pneumonia and Kaposi sarcoma, has been reported. ${ }^{25,26}$ Monitoring of CD4 counts and antibiotic prophylaxis with trimethroprim/sulfametoxazole or pentamidine inhalations for patients at risk have been proposed.

\section{Temozolomide for patients with newly diagnosed glioblastoma}

Based on the activity in recurrent glioma and in vitro data suggesting additive or supra-additive activity when TMZ was administered concomitantly with radiotherapy, a phase II trial investigated the administration of low-dose TMZ daily $(75 \mathrm{mg} /$ $\mathrm{m}^{2}$ daily $7 / 7$ days week) with concomitant radiotherapy for up to 7 weeks, followed by six cycles of adjuvant TMZ (5-days q28 days). This treatment was shown to be feasible and well 
tolerated. $^{26}$ The European Organisation for Research and Treatment of Cancer (EORTC) and the National Cancer Institute of Canada (NCIC) Clinical Trials Group compared this new combined modality regimen to standard radiotherapy alone in a large prospective randomized phase III trial on 573 patients. ${ }^{4}$ Primary trial endpoint was survival. This study unequivocally demonstrated that the combination of TMZ and radiotherapy (RT) followed by up to six cycles of adjuvant TMZ improves survival. With combined modality treatment, the 2-year survival increased from $10 \%$ to $26 \%$ (Table 1). Subgroup analyses suggested that patients of all age groups (up to age 70 allowed in the trial) and independent of prior tumour resection benefited from this treatment. As in other fields of oncology, patients with a modest performance status did not benefit from the addition of chemotherapy. Overall, the combined treatment was well tolerated, and the main reason for early discontinuation was disease progression.

The clinical relevance of the mechanistic implication of the DNA repair enzyme MGMT in alkylating chemotherapy was tested in this randomized EORTC/NCIC trial. Samples from 206 patients could be analysed for the status of the MGMT gene promoter using methylation-specific PCR (MSP). ${ }^{27}$ In $45 \%$ of tumour samples, the MGMT gene promoter was methylated, and the gene was silenced. Overall, patients with a silenced MGMT gene had longer survival. Break down of the data by treatment strongly suggests that the MGMT methylation status is a predictive marker for benefit from TMZ chemotherapy. For patients in the TMZ/RT arm, the 2year survival rate was $46 \%$ when their tumour presented a methylated MGMT status in contrast to only $14 \%$ in patients with an unmethylated MGMT gene promoter (Table 2). Thus, in this molecularly defined subgroup the TMZ is even more effective increasing the median survival by 9 months to 21.7, while patients with an unmethylated MGMT gene promoter had little, if any, TMZ-derived benefit with a median survival of 12.7 months.

Confirmation of these results in a second trial would then suggest that only patients whose tumours comprise a methylated MGMT promoter (thus silenced gene) should receive TMZ, while for other patients, alternative strategies must be considered. Strategies aiming at overcoming MGMT-mediated resistance are currently developed. Administration of agents like O6-benzyl-guanine, a non-cytotoxic substrate of MGMT, or in combination with nitrosoureas is limited by increased systemic toxicity, mainly myelosuppression. Continuous administration of temozolomide has been shown to deplete intracellular MGMT and novel dose-dense schedules are currently explored as adjuvant treatment in large randomized trials.
Current phase II and phase III studies are investigating whether the addition of agents targeting the EGF receptor pathway (e.g., the tyrosin kinase inhibitor erlotinib), VEGF and PDGF receptors (e.g., PTK787) or the tumour vasculature (e.g., the alphaVbeta3 inhibitor cilengitide) to the combination of TMZ and radiotherapy further improve survival in newly diagnosed GBM.

\section{Temozolomide in elderly}

The first randomized studies on anaplastic glioma have clearly shown the superiority of radiotherapy over chemotherapy. ${ }^{1}$ However, in elderly patients with a particularly dismal prognosis, simple and least toxic therapies are required. Encouraged by reports of high response and disease stabilization rates with TMZ chemotherapy in previously untreated GBM patients, ${ }^{28}$ chemotherapy in lieu of radiotherapy has been evaluated in a limited number of patients in uncontrolled trials. ${ }^{29}$ Chinot and colleagues reported a median survival of 6.4 month in a prospective study on 32 patients. ${ }^{29}$ Glantz and colleagues observed in a non-randomized study a survival outcome after treatment with temozolomide $(n=32)$ that was at least as good as 'historical controls' treated with radiotherapy in the same time period within the same institution. ${ }^{30}$ Furthermore, both groups were comparable with respect to known prognostic factors. The treatment outcome of these two studies appears similar compared to the results of radiotherapy only in elderly or poor prognosis GBM patients. ${ }^{31,32}$ In both studies toxicity was modest, although in one study dose delays and dose reductions were needed in $38 \%$ and $13 \%$ of patients. This underlines that a more cautious approach to chemotherapy is needed in elderly patients. Both studies give support for further investigations into this approach. The NCIC together with the EORTC are currently planning a randomized trial comparing standard hypofractionated radiotherapy with $\mathrm{TMZ}$ added to the same $\mathrm{RT}$, or TMZ alone.

\section{Temozolomide in combination with other cytotoxic agents}

In the past years results, of several novel combinations of alkylating agents with drugs with a different mode of action investigated in recurrent GBM have been published: cisplatin and $\mathrm{TMZ}^{33}$ marimastat and $\mathrm{TMZ}^{34}$ cisretinoic acid and $\mathrm{TMZ}^{35}$ thalidomide and carmustine ${ }^{36}$ (Table 3). Each of these combinations report high response rates and favourable percentages of patients free from progression at six months. Invariably, the authors conclude the results are promising, and then move on to the next combination. In the absence

\begin{tabular}{|c|c|c|c|c|}
\hline \multirow[t]{2}{*}{ Treatment } & \multicolumn{2}{|c|}{ Median survival (months) } & \multicolumn{2}{|c|}{ Two year survival (\%) } \\
\hline & Radiotherapy $^{\mathrm{a}}$ & $\begin{array}{c}\text { Radiotherapy } \\
\text { plus temozolomide }\end{array}$ & Radiotherapy $^{\mathrm{a}}$ & $\begin{array}{l}\text { Radiotherapy plus } \\
\text { temozolomide }\end{array}$ \\
\hline Unmethylated MGMT promotor & 11.8 & 12.7 & $<2$ & 13.8 \\
\hline Methylated MGMT promotor & 15.3 & 21.7 & 22.7 & 46 \\
\hline
\end{tabular}


Table 3 - A summary of recent studies on recurrent glioblastioma multiforme, except for *, recurrent anaplastic astrocytoma

\begin{tabular}{|c|c|c|c|c|}
\hline & Drugs & $n$ & $\mathrm{CR}+\mathrm{PR}(\%)$ & 6 mo PFS (\%) \\
\hline \multirow[t]{2}{*}{ Yung et al. ${ }^{16}$} & TMZ $150-200 \mathrm{mg} / \mathrm{m}^{2}$ day $1-5$ every 4 weeks & 112 & 5.4 & 21 \\
\hline & Procarbazine & 113 & 5.3 & 8 \\
\hline Yung $^{15^{*}}$ & TMZ $150-200 \mathrm{mg} / \mathrm{m}^{2}$ day $1-5$ every 4 weeks & 162 & 35 & 46 \\
\hline Jaeckle $^{35}$ & TMZ $150-200 \mathrm{mg} / \mathrm{m}^{2}$ day $1-5$ every 4 weeks + cis retinoic acid & 40 & 4.5 & 32 \\
\hline Groves $^{34}$ & TMZ $150-200 \mathrm{mg} / \mathrm{m}^{2}$ day $1-5$ every 4 weeks + marimastat & 44 & 13.6 & 39 \\
\hline Fine $^{36}$ & BCNU $200 \mathrm{mg} / \mathrm{m}^{2}+800-1200 \mathrm{mg}$ thalidomide every 6 weeks & 40 & 24 & 27 \\
\hline Brandes $^{33}$ & TMZ $200 \mathrm{mg} / \mathrm{m}^{2}$ day $1-5+$ cisplatin $75 \mathrm{mg} / \mathrm{m}^{2}$ every 4 weeks & 50 & 20 & 34 \\
\hline Wick $^{23}$ & $\mathrm{TMZ} 150 \mathrm{mg} / \mathrm{m}^{2}$ one week on/one week off & 21 & 10 & 43 \\
\hline Khan $^{22}$ & $\mathrm{TMZ} 75 \mathrm{mg} / \mathrm{m}^{2}$ daily for 6 weeks in 10 week cycles & 28 & 0 & 19 \\
\hline Prados $^{41}$ & BCNU $150 \mathrm{mg} / \mathrm{m}^{2}+\mathrm{TMZ}$ single dose $550 \mathrm{mg} / \mathrm{m}^{2}$ & 36 & 5.5 & 21 \\
\hline Brandes $^{61}$ & BCNU $80 \mathrm{mg} / \mathrm{m}^{2}$ day $1-3$ & 40 & 15 & 17.5 \\
\hline Brandes $^{62}$ & $\begin{array}{l}\text { BCNU } 100 \mathrm{mg} / \mathrm{m}^{2} \text { day } 1+175 \mathrm{mg} / \mathrm{m}^{2} \mathrm{CPT}-11 \\
\text { weekly for } 4 \text { weeks in cycles of } 6 \text { weeks }\end{array}$ & 42 & 21.4 & 30 \\
\hline Kappele $^{63}$ & PCV & 63 & 11 & 29 \\
\hline
\end{tabular}

Abbreviations: $n$, number of patients; CR, complete response; PR, partial response; PFS, progression-free survival; BCNU, curmustine; TMZ, temozolomide; PCV, procarbazine, CCNU and vincristine.

of randomized trials, no conclusion can be drawn from these studies and results may solely reflect patient selection.

Because of the role of MGMT in the resistance to alkylating chemotherapy, several studies added a MGMT depleting agent in order to increase efficacy. For this purpose, both drugs with intrinsic cytotoxic activity as well as drugs that only deplete MGMT (O6-benzylguanine; O6-BG) were used. As one might expect, such combinations also increased toxicity and necessitated the use of reduced dosages as compared to the same agents when given as single agent treatment. ${ }^{37,38}$ First results of this strategy showed that adding O6-BG to carmustine did not induce regression in carmustine resistant gliomas, although a similar trial in temozolomide pretreated patients showed some evidence of benefit by adding O6-BG to TMZ. ${ }^{39,40}$ A trial exploring the combination BCNU and temozolomide concluded however that the outcome of the combination appeared of similar efficacy as single agent temozolomide (Table 3). ${ }^{41}$

\section{Irinotecan}

Since its initial report of activity (of irinotecan CPT11) in recurrent malignant glioma ( $17 \%$ objective response rate in GBM), this drug was further explored in several single agent studies. ${ }^{42-44}$ These did not confirm the high response rates initially reported. Currently combinational regimens are being investigated, in particular of temozolomide and irinotecan. A study investigating the combination, BCNU and irinotecan, yielded a response rate similar to other combination studies with temozolomide. As irinotecan is mainly metabolized in the liver, dependent on the P450 system, it can only be reliably administered to patients not using hepatic enzyme inducing antieptileptic drugs (EIAED).

\section{Oligodendroglioma}

Oligodendroglioma and to a lesser extent, oligoastrocytoma, are responsive to chemotherapy. Two-thirds of patients with recurrent tumours were shown to respond to PCV chemother- apy, consisting of procarbazine, CCNU and vincristine. ${ }^{45,46}$ The recent finding of a high percentage of these tumours with a methylated MGMT status ( $>80 \%$ ) may in part explain this clinical feature. ${ }^{47}$ Further molecular studies showed that in particular, patients with oligodendrogliomas with loss of heterozygosity on both, the short arm of chromosome 1 (1p) and the long arm of chromosome 19 (19q), are very sensitive to PCV chemotherapy: almost all patients responded to PCV chemotherapy. ${ }^{48,49}$ The EORTC conducted two phase II trials evaluating single agent standard schedule TMZ as first and second-line therapy in patients with recurrent or progressive anaplastic oligodendroglioma and oligoastrocytoma. ${ }^{50,51} \mathrm{High}$ response rates of $53 \%$ ( $26 \%$ complete responses) and $25 \%$ were observed to first and second-line temozolomide chemotherapy, respectively. Genetic analysis confirmed the importance of $1 \mathrm{p} / 19 \mathrm{q}$ loss for chemotherapy response also for TMZ. ${ }^{52}$ The currently available data suggest that about $55-65 \%$ of patients with recurrent oligodendroglioma respond to first-line chemotherapy, but in second-line the response rate dropped to $20-25 \%$ regardless of the chosen sequence of treatment: temozolomide first or PCV first.

Both the RTOG and the EORTC investigated the addition of PCV chemotherapy to radiotherapy in newly diagnosed anaplastic oligodendroglioma. ${ }^{53}$ The RTOG study used neoadjuvant with a dose intensified PCV schedule, whereas the EORTC study used classical adjuvant design with standard PCV; in both studies the control arm received radiotherapy only (but further treatment at the time of progression was left to the discretion of the treating physician). Most patients received further chemotherapy at the time of progression. Although both studies observed an increase in progressionfree survival in the PCV arm, this did not translate in to an increase in overall survival. Patients with $1 p / 19 q$ loss had a clearly better outcome (median survival over 6-7 years as compared to 2-3 years in patients without $1 p / 19 q$ loss), but the improved outcome was regardless of treatment. Both studies showed, that in this chemosensitive tumour, the timing of chemotherapy was not relevant (at first diagnosis or at recurrence), as long as it was given. 
The somewhat counter-intuitive result of three large studies on adjuvant treatment in glioma is that the EORTC study, on concurrent and adjuvant temozolomide in chemoresistant GBM, resulted in survival benefit, whereas a similar EORTC and RTOG trials on chemosensitive oligodendroglioma failed to provide survival benefit. Perhaps the most significant difference between these trials is the combination of radiotherapy with daily temozolomide in the GBM study. It may well be that this part of the treatment is the essential part for the improved outcome, but this must be proven in new trials.

Despite the absence of a formal trial many clinicians today propose upfront temozolomide TMZ as first treatment in 1p/19q loss oligodendroglioma. This is clearly an experimental approach, based on the assumption that RT is likely to induce delayed cognitive deficits. This assumption is questionable though if modern RT techniques are used with dose fractions of less than $2 \mathrm{~Gy} .{ }^{54}$ Eventually, this may be more a matter of side-effects, and one should realize that especially for limited size lesions, RT offers an effective treatment of short duration (6 weeks instead of 12-24 months of chemotherapy).

\section{Low-grade glioma}

Several recently published studies have explored upfront treatment of newly diagnosed low-grade glioma (in particular oligodendroglioma) with chemotherapy with either PCV or temozolomide. ${ }^{55-58}$ These trials show that objective responses are rare, despite prolonged disease stabilization in the majority of patients. Measuring response in low-grade tumours in the absence of contrast enhancement may be particularly difficult. On MRI abnormalities on T2 weighted images are unlikely to decrease significantly, and functional imaging by positron-emission tomography using amino-acid tracers is not widely available. ${ }^{56}$ For clinical trials, time to progression may be the preferred endpoint. ${ }^{59,60}$

Whether there is truly an advantage in treating these patients with upfront chemotherapy compared to initial RT is currently the subject of a randomized EORTC/NCIC phase III trial. Outside trials, it is questionable whether upfront chemotherapy should be given to low-grade glioma (LGG) patients, even in case of oligodendroglioma with 1p/19q LOH. Radiotherapy is also a very effective and proven treatment, and in the end, the choice of therapy may well be a matter of acute and long-term toxicity based on individual patient factors and tumour size and location. Whether a short course of radiotherapy (typically 6 weeks) should be replaced by prolonged (proposed duration 1 year) and costly administration of chemotherapy needs to be proven. Possibly the sequence of treatment modalities is of lesser or no importance in overall survival. Although the addition of TMZ to radiotherapy has been proven superior in the treatment of aggressive glioblastoma, extending this approach to low-grade glioma is potentially harmful. In a disease with median survival rates of 5-7 years, with a significant proportion of patients living 10-15 years or longer, late toxicity of any treatment is a concern. Here the sequential and prudent use of the treatment modalities may be more optimal than the maximum use of all therapeutic arms upfront.

\section{Conclusions and outlook}

Temozolomide has become the mainstay of chemotherapeutic treatment of high-grade glioma. The use of a cytotoxic agent with the capacity of crossing the blood-brain barrier in combination with radiotherapy has a clear impact on progression and survival of glioblastoma patients. Molecular studies have shown that specific tumour characteristics like a silenced MGMT gene may allow tailoring treatment for individual patients. New trials are planned to confirm these findings, but also to develop strategies allowing depletion of MGMT in unmethylated tumours, e.g., by using more intensive treatment schedules, but also to evaluate the role adjuvant treatment after the completion of concurrent chemoirradiation.

The current progress in the treatment of malignant glioma should fuel interest in further improving the outcome of patients with brain tumours. Optimizing current agents and treatment regimens, combination with new cytotoxic and targeted molecules hold promise. The close interaction and integration of laboratory findings and clinical research will allow to identifying new treatment targets and are a prerequisite for individual treatment decisions in the future. The ongoing EORTC/NCIC randomized trial in low-grade glioma is a good example.

Optimal management of patients with brain tumours requires an integrated and multidisciplinary approach. Despite the recent progress and the successful introduction of temozolomide in clinical practice, further research and development of appropriate agents is still needed. Correlative laboratory studies will help for better understanding of successes and failures.

\section{Conflict of interest statement}

None declared.

\section{R E F E R E N C E S}

1. Walker MD, Alexander E, Hunt WE, et al. Evaluation of BCNU and/or radiotherapy in the treatment of anaplastic gliomas. A cooperative clinical trial. J Neurosurg 1978;49:333-43.

2. Walker MD, Green SB, Byar DP, et al. Randomized comparisons of radiotherapy and nitrosoureas for the treatment of malignant glioma after surgery. N Engl J Med 1980;303:1323-9.

3. Glioma Meta-Analysis Group. Chemotherapy in adult high-grade glioma: a systematic review and meta-analysis of individual patient data from 12 randomised trials. Lancet 2002;359:1011-8.

4. Stupp R, Mason WP, van den Bent MJ, et al. Radiotherapy plus concomitant and adjuvant temozolomide for glioblastoma. $\mathrm{N}$ Engl J Med 2005;352:987-96.

5. Ostermann S, Csajka C, Buclin T, et al. Plasma and cerebrospinal fluid population pharmacokinetics of temozolomide in malignant glioma patients. Clin Cancer Res 2004;10:3728-36.

6. Brada M, Judson I, Beale P, et al. Phase I dose-escalation and pharmacokinetic study of temozolomide (SCH 52365) for refractory or relapsing malignancies. $\mathrm{Br} \mathrm{J}$ Cancer 1999;81:1022-30. 
7. Gerson SL. MGMT: its role in cancer aetiology and cancer therapeutics. Nature Rev 2004;4:296-307.

8. Liu L, Allay E, Dumenco LL, et al. Rapid repair of O6-methylguanine-DNA adducts protects transgenic mice from $\mathrm{N}$-methylnitrosourea-induced thymic lymphomas. Cancer Res 1994;54:4648-52.

9. Belanich M, Randall T, Pastor MA, et al. Intracellular localization and intracellular heterogeneity of the human DNA repair protein 06-methylguanine-DNA methyltransferase. Cancer Chemother Pharm 1996;37:547-55.

10. Jaeckle KA, Eyre HJ, Townsend JJ, et al. Correlation of tumour O6 methylguanine-DNA methyltransferase levels with survival of malignant astrocytoma patients treated with bis-chloroethylnitrosourea: a southwest oncology group study. J Clin Oncol 1999;16:3310-5.

11. Belanich M, Pastor M, Randall T, et al. retrospective study of the correlation between DNA repair protein alkyltransferase and survival of brain tumour patients treated with carmustine. Cancer Res 1996;56:783-8.

12. Silber JR, Mueller BA, Eweres TG, et al. Comparison of O6-methylguanine-DNA methyltransferase activity in brain tumours and in adjacent normal brain. Cancer Res 1993;53:3416-20.

13. Esteller M, Garcia-Foncillas J, Andion E, et al. Inactivation of the DNA-repair gene MGMT and the clinical response of gliomas to alkylating agents. N Engl J Med 2000;343:1350-4.

14. Hegi ME, Diserens A-C, Godard S, et al. Clinical trial substantiates the predictive value of O-6-methylguanine-DNA methyltransferase promoter methylation in glioblastoma patients treated with temozolomide. Clin Cancer Res 2004;15:1871-4.

15. Yung WKA, Prados M, Yaya-Tur R, et al. Multicenter phase II trial of temozolomide in patients with anaplastic astrocytoma or anaplastic oligoastrocytoma at first relapse. J Clin Oncol 1999;17:2762-71.

16. Yung WKA, Albright RE, Olson J, et al. A phase II study of temozolomide vs. procarbazine in patients with glioblastoma multiforme at first relapse. Br J Cancer 2000;83:588-93.

17. Brada M, Hoang-Xuan K, Rampling R, et al. Multicenter phase II trial of temozolomide in patients with glioblastoma multiforme at first relapse. Ann Oncol 2000;12:259-66.

18. Brock CS, Newlands ES, Wedge SR. Phase I trial of Temozolomide using an extende continuous oral schedule. Cancer Res 1998;58:4363-7.

19. Vera K, Djafari L, Faivre S, et al. Dose-dense regimen of temozolomide given every other week in patients with primary central nervous system tumours. Ann Oncol 2004;15:161-71.

20. Spiro TP, Liu L, Majka S, et al. Temozolomide: the effect of once- and twice-a-day dosing on tumour tissue levels of the DNA repair protein O(6)-alkylguanine-DNA-alkyltransferase. Clin Cancer Res 2001;7:2309-17.

21. Tolcher AW, Gerson SL, Denis L, et al. Marked inactivation of O6-alkylguanine-DNA alkyltransferase activity with protracted temozolomide schedules. Br J Cancer 2003;88:1004-11.

22. Khan RB, Raizer JJ, Malkin MG, et al. A phase II study of extended low-dose temozolomide in recurrent malignant gliomas. Neuro-Oncology 2002;4:39-43.

23. Wick W, Steinbach JP, Küker WM, et al. One week on/one week off: a novel active regimen of temozolomide for recurrent glioblastoma. Neurology 2004;62:2113-5.

24. Su YB, Sohn S, Krown SE, et al. Selective CD4+ lymphopenia in melanoma patients treated with temozolomide: a toxicity with therapeutic implications. J Clin Oncol 2004;15:610-6.

25. Mahindra AK, Grossman SA. Pneumocystis carinii pneumonia in HIV negative patients with primary brain tumours. J Neuro-Oncol 2003;63:263-70.
26. Stupp R, Dietrich P-Y, Osterman-Kraljevic S, et al. Promising survival for patients with newly diagnosed glioblastoma multiforme treated with concomitant radiation plus temozolomide followed by adjuvant temozolomide. J Clin Oncol 2002;20:1375-82.

27. Hegi ME, Diserens A-C, Gorlia T, et al. MGMT gene silencing and benefit from temozolomide in glioblastoma. $N$ Engl J Med 2005;352:997-1003.

28. Friedman HS, McLendon RE, Kerby T, et al. DNA mismatch repair and 06-alkylguanine-DNA alkyltransferase and response to temodal in newly diagnosed malignant glioma. J Clin Oncol 1998;16:3851-7.

29. Chinot O-L, Barrie M, Frauger E, et al. Phase II study of temozolomide without radiotherapy in newly diagnosed glioblastoma multiforme in elderly populations. Cancer 2004;100:2208-14.

30. Glantz M, Chamberlain M, Liu Q et al. Temozolomide as an alternative to irradiation for elderly patients with newly diagnosed malignant gliomas. Cancer 2003;97:2262-6.

31. Roa W, Brasher PMA, Bauman G, et al. Abbreviated course of radiation therapy in older patients with glioblastoma multiforme: a prospective randomized clinical trial. J Clin Oncol 2004;22:1583-8.

32. Chang EL, Yi W, Allen PK, et al. Hypofractionated radiotherapy for elderly or younger low-performance status glioblastoma patients: outcome and prognostic factors. Int $J$ Radiat Oncol Biol Phys 2003;56:519-28.

33. Brandes AA, Basso U, Reni M, et al. First-line chemotherapy with cisplatin plus fractionated temozolomide in recurrent glioblastoma multiforme: a phase II study of the Gruppo Italiano Cooperativo di Neuro-Oncologia. J Clin Oncol 2004;22:1598-604.

34. Groves MD, Puduvalli VK, Hess KR, et al. Phase II trial of temozolomide plus the matrix metalloproteinase inhibitor, marimastat, in recurrent and progressive glioblastoma multiforme. J Clin Oncol 2002;20:1383-8.

35. Jaeckle KA, Hess KR, Yung WKA, et al. Phase II evaluation of temozolomide and 13-cis-retinoic acid for the treatment of recurrent and progressive malignant glioma: a North American Brain Tumour Consortium Study. J Clin Oncol 2003;21:2305-11.

36. Fine HA, Wen PY, Maher EA, et al. Phase II trial of thalidomide and carmustine for patients with recurrent high-grade gliomas. J Clin Oncol 2003;21:2299-304.

37. Quinn JA, Pluda J, Dolan ME, et al. Phase II trial of carmustine plus $\mathrm{O}^{6}$-benzylguanine for patients with nitrosourea-resistant recurrent or progressive malignant glioma. J Clin Oncol 2002;20:2277-83.

38. Clifford Schold Jr S, Kuhn JG, Chang SM, et al. A phase I trial of 1,3-bis(2-chloroethyl)-1-nitrosourea plus temozolomide: a North-American brain tumour consortium study. Neuro-Oncology 2000;2:34.

39. Friedman HS, Pluda J, Quinn JA, et al. Phase I trial of carmustine plus $\mathrm{O}^{6}$-benzylguanine for patients with recurrent or progressive malignant glioma. J Clin Oncol 2000;18:3522-8.

40. Quinn JA, Desjardins A, Reardon D, et al. Phase II trial of temozolomide (temodar) plus O6-benzylguanine in the treatment of patients with temodar-resistant malignant glioma. Neuro-Oncology 2004;6:380. (Abstract TA-45).

41. Prados MD, Yung WKA, Fine HA, et al. Phase 2 study of BCNU and temozolomide for recurrent glioblastoma multiforme: North American Brain Tumour Consortium study. Neuro-Oncology 2004;6:33-7.

42. Friedman HS, Petros WP, Friedman A, et al. Irinotecan therapy in adults with recurrent or progressive malignant glioma. J Clin Oncol 1999;17:1516-25.

43. Raymond E, Fabbro M, Boige V, et al. Multicentre phase II study abd pharmacokinetic analysis of irinotecan in 
chemotherapy-naive patients with glioblastoma. Ann Oncol 2003;14:603-14.

44. Chamberlain M. Salvage chemotherapy with CPT-11 for recurrent glioblastoma multiforme. J Neuro-Oncol 2002;56:183-8.

45. Cairncross G, Macdonald D, Ludwin S, et al. Chemotherapy for anaplastic oligodendroglioma. J Clin Oncol 1994;12:2013-21.

46. van den Bent MJ, Kros JM, Heimans JJ, et al. Response rate and prognostic factors of recurrent oligodendroglioma treated with procarbazine, CCNU and vincristine chemotherapy. Neurology 1998;51:1140-5.

47. Möllemann M, Wolter M, Felsberg J, et al. Frequent promotor hypermethylation and low expression of the MGMT gene in oligodendroglial tumours. Int J Cancer 2004;113:379-85.

48. Cairncross JG, Ueki K, Zlatescu MC, et al. Specific genetic predictors of chemotherapeutic response and survival in patients with anaplastic oligodendrogliomas. J Natl Cancer Inst 1998;90:1473-9.

49. van den Bent MJ, Looijenga LHJ, Langenberg $\mathrm{K}$, et al. Chromosomal anomalies in oligodendroglial tumours are correlated with clinical features. Cancer 2003;97:1276-84.

50. van den Bent MJ, Taphoorn MJ, Brandes AA, et al. Phase II study of first-line chemotherapy with temozolomide in recurrent oligodendroglioma: the European Organisation of Research and Treatment of Cancer Brain Tumour Group study 26971. J Clin Oncol 2003;21:2525-8.

51. van den Bent MJ, Chinot O, Boogerd W, et al. Second-line chemotherapy with Temozolomide in recurrent oligodendroglioma after PCV (procarbazine, lomustine and vincristine) chemotherapy: EORTC Brain Tumour Group phase II study 26972. Ann Oncol 2003;14:599-602.

52. Triebels V, Taphoorn MJB, Brandes AA, et al. Response to 2nd line PCV chemotherapy in recurrent oligodendroglioma after 1st line temozolomide. Neurology 2004;63:904-6.

53. Cairncross JG, Seiferheld W, Shaw E, et al. An intergroup randomized controlled clinical trial (RCT) of chemotherapy plus radiation (RT) versus RT alone for pure and mixed anaplastic oligodendrogliomas: initial report of RTOG 94-02. Proc Am Soc Clin Oncol 2004;23:107. (Abstract \# 1500).
54. Klein M, Heimans JJ, Aaronson NK, et al. Effect of radiotherapy and other treatment-related factors on mid-term to long-term cognitive sequelae in low-grade gliomas: a comparative study. Lancet 2002;360:1361-8.

55. Brada M, Viviers L, Abson C, et al. Phase II study of primary temozolomide chemotherapy in patients with WHO grade II gliomas. Ann Oncol 2003;14:1715-21.

56. Biemond-ter Stege E, Kros JM, de Bruin HG, et al. Treatment of low-grade oligodendroglial tumours with PCV chemotherapy. Cancer 2005;103:802-9.

57. Buckner JC, Gesme D, O'Fallon JR, et al. Phase II trial of procarbazine, lomustine, and vincristine as initial therapy for patients with low-grade oligodendroglioma or oligoastrocytoma: efficacy and and associations with chromosomal abnormalities. J Clin Oncol 2003;21: 251-5.

58. Hoang-Xuan K, Capelle L, kujas M, et al. Temozolomide as initial treatment for adults with low-grade oligodendrogliomas or oligoastrocytomas and correlation with chromosome $1 p$ deletions. J Clin Oncol 2004;22:3133-8.

59. Pace A, Vidiri A, Galie E, et al. Temozolomide chemotherapy for progressive low-grade glioma: clinical benefits and radiological response. Ann Oncol 2003;14: 1722-6.

60. Quinn JA, Reardon DA, Friedman AH, et al. Phase II trial of temozolomide in patients with progressive low-grade glioma. J Clin Oncol 2003;21:646-51.

61. Brandes AA, Tosoni A, Amista $\mathrm{P}$, et al. How effective is BCNU in recurrent glioblastoma in the modern era? A phase II trial. Neurology 2004;63:1281-4.

62. Brandes AA, Tosoni A, Basso U, et al. Second-line chemotherapy with irinotecan plus carmustine in glioblastoma recurrent or progressive after first-line temozolomide chemotherapy: a phase II study of the Gruppo Italiano Cooperativo di Neuro-Oncologia (GICNO). J Clin Oncol 2004;22:4779-86.

63. Kappele AC, Postma TJ, Taphoorn MJ, et al. PCV chemotherapy for recurrent glioblastoma multiforme. Neurology 2001;56:118-20. 